\title{
Desenvolvimento de conceitos científicos nos Anos Iniciais: movimentos na/pela linguagem
}

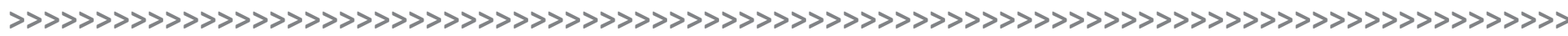

Débora Ferrari Martinez*

\begin{abstract}
Resumo:
Neste artigo, analisamos os processos de aquisição do conhecimento científico em propostas envolvendo produção oral e escrita, na esfera escolar. Situamos nosso debate dentro da perspectiva sócio-histórica, compreendendo que o desenvolvimento e a aprendizagem estão em constante interlocução. No intuito de demonstrar como as crianças protagonizam o desenvolvimento de formação de conceitos, trazemos registros de observação de uma sala de aula de segundo ano do Ensino Fundamental. Concluímos que quando a ênfase pedagógica é posta no aspecto relacional dos sujeitos com a linguagem e destes entre si, no processo de elaboração conceitual, os conhecimentos acabam construídos em um plano de "negociação" de sentidos, no qual a condição do aluno que aprende se define na interlocução com colegas e professoras na busca potencial para os sentidos dos objetos em aprendizagem.
\end{abstract}

\section{Palavras-chave:}

Aquisição da escrita. Aprendizagem. Elaboração conceitual. Interlocução. Ensino de Ciências.

\section{Resumén:}

En este artículo analizamos los procesos de adquisición de conocimiento científico en propuestas que impliquen la producción oral y escrita, en el ámbito de la educación. Situamos nuestro debate dentro de la perspectiva socio-histórica, entendiendo que el desarrollo y el aprendizaje están en constante diálogo. A fin de demostrar cómo los niños juegan el desarrollo de la formación de los conceptos, apresentamos registros de observación de un aula de segundo año de educación básica. Llegamos a la conclusión de que cuando la parte pedagógica se hace hincapié en el aspecto relacional de los sujetos con el lenguaje y de estos entre sí, en el proceso de conocimiento conceptual están integrados en un plan de "negociación" de los sentidos, en el que la condición del estudiante aprende se define en la interlocución con colegas y profesores en la búsqueda de los significados de los objetos de aprendizaje.

\section{Palabras-clave:}

Adquisición de la escritura. Aprendizaje. Elaboración conceptual. Interloción. Enseñanza de las Ciências.

Neste artigo analisamos as possibilidades de ensino e aprendizagem do conhecimento científico na esfera escolar, tomando como base o trabalho com os textos de alunos dos anos iniciais do ensino fundamental. Como prática social específica, o discurso das ciências é, muitas vezes, apresentado e/ou sistematizado no âmbito dos anos iniciais. A
* > Mestra em Educação pela Universidade Federal de Santa Catarina, professora da área dos Anos Iniciais do Colégio de Aplicação da UFRGS. E-mail: profdeboracap@ gmail.com. 
escrita é um dos meios para que os professores alcancem os objetivos de aprendizagem na área das ciências. Portanto, torna-se relevante analisar movimentos de aprendizagem das ciências nos anos iniciais pelo viés da análise dos processos de linguagem envolvidos nas cenas de sala de aula.

A fim de delimitar o referencial teórico aqui utilizado, apresentamos uma abordagem dentro da perspectiva sócio-histórica, tomando referenciais de Vigotski e Bakhtin na análise dos movimentos de produção de linguagem e possibilidades de aprendizagem de conceitos.

\section{Desenvolvimento e aprendizagem: a perspectiva sócio-histórica}

A periodização da infância é apresentada na obra de Vigotski (1997) como uma forma de mapear os movimentos do processo de desenvolvimento infantil. Sua investigação em busca da compreensão dessas etapas levou-o a dividir ou distribuir os fatores de passagem entre as diversas idades das crianças, em uma crítica às teorias fundamentadas apenas em fatores orgânicos ${ }^{1}$. Vigotski (1997) utiliza o termo crise, a fim de deixar claro que cada etapa do desenvolvimento nega as propriedades da anterior, mas, ao mesmo tempo, a anterior continua existindo dentro da etapa subsequente. A crise poderia ser considerada um indício de um movimento de virada qualitativa, sendo precedida por momentos de estabilidade.

O foco de Vigotski (1997) é dirigido a essas novas formações que despontam em cada etapa de desenvolvimento e ao modo de o sujeito relacionar-se com a cultura. Para cada período etário há um grupo de funções psicológicas que estão em desenvolvimento e que levarão à reestruturação das funções existentes para a formação de uma nova estrutura, todas estas sendo analisadas quanto à sua função peculiar e associadas às funções sociais.

Em cada uma das etapas, Vigotski (1997) sugere haver uma situação social como mote para o desenvolvimento, ou seja, fatores orgânicos e sociais formados de linhas centrais e acessórias que condicionam e estimulam o desenvolvimento. A estrutura da situação social formadora do desenvolvimento deve refletir-se na criança como um todo, isto é, como uma pessoa que se encontra engajada nas relações sociais com outras pessoas; não apenas em termos de descrição de qualidades da criança, mas da interação da criança com seu ambiente.

A situação social do desenvolvimento não é, necessariamente, condição ou pré-requisito para uma próxima etapa, mas sim o núcleo para compreender as relações interfuncionais das crianças com o mundo simbólico. Dizendo de outra forma, para chegar ao entendimento de uma situação social do desenvolvimento é necessário entender o cenário onde o desenvolvimento ocorre, em que se tecem as teias dos signos e significações em cada etapa. Isso se torna pressuposto para compreender a criança não como ser receptor passivo de estímulos externos, mas partícipe do conjunto de ações e interesses material e historicamente motivados, situação que se reflete no período etário em que se encontra.

Das reflexões de Vigotski (1997) em torno desses períodos, destacamos a que diz respeito à crise dos sete anos, pois se situa na etapa das crianças do segundo ano do ensino fundamental, grupo em relação ao qual trazemos as reflexões deste artigo. A criança nessa idade, comumente elabora a conversão da fala comunicativa e espontânea (da criança pequena), em discurso interno do pensamento verbalizado. O discurso interno, destacamos, não surge apenas nessa fase, mas torna-se consciente para a criança e começa a delinear-se como centro do seu psiquismo. Cresce, portanto, a diferenciação entre mundo interno e mundo externo, bem como a possibilidade de efetuar generalizações, tanto de temas das vivências subjetivas como das funções intelectuais e simbólicas. A criança é capaz 
de analisar suas vivências, seus estados subjetivos e de fazer projeções. Vigotski (1997) entende que este é um período de crise, pois são estabelecidas "lutas internas" relativas às escolhas que a criança pode tomar em relação às ações que podem ser efetivadas.

Considerando a reflexão efetuada acima, podemos afirmar que, em direção oposta a correntes que acreditam processar-se o desenvolvimento de dentro para fora (do individual para o social), ou seja, que a criança está pronta e à espera de estímulos "corretos" que tragam à tona determinadas funções complexas de comportamento, os autores da perspectiva sócio-histórica defendem o movimento dialético do desenvolvimento entre o estado intra e o interpsicológico. Este é um pressuposto importante para as teorias do desenvolvimento que se ocupam com o campo educacional. Cada campo da cultura humana, a exemplo da escola, é impregnado de signos e significados. As crianças pertencentes a comunidades escolares tornam-se partícipes das relações sociais dessa e nessa esfera social. Portanto, instrumentos e símbolos construídos socialmente definem quais das inúmeras possibilidades de funcionamento das funções psicológicas superiores serão efetivamente concretizadas ao longo do desenvolvimento desse público escolar, quando em processo de ensino e aprendizagem sistematizados, movimento que poderá contribuir para o desenvolvimento de cada uma das pessoas partícipes dessa esfera de atividade humana. Para Vigotski (2000), “[o] movimento real do processo de desenvolvimento do pensamento infantil não se realiza do individual para o socializado, mas do social para o individual" (VIGOTSKI, 2000, p. 67).

A criança como ser social, que partilha experiências de diferentes naturezas com o outro (relação dialógica). A linguagem ocupa lugar de preponderância no processo de constituição do ser humano como ser social. Tanto para Bakhtin quanto para Vigotski, a linguagem não apenas é um meio pelo qual os signos circulam, mas também o elemento mediador entre a criança e o outro, entre a criança e o mundo que a cerca. Em última instância, o meio pelo qual a criança se situa no mundo.

O desenvolvimento humano, portanto, configura-se na cena social em que o indivíduo, de forma ativa com o mundo simbólico, pela mediação semiótica, se relaciona com o outro. Em cada etapa da vida da criança, o caráter dessa relação social se modifica, reestruturando-se à medida que novos elementos simbólicos, apreendidos na convivência com o outro, são convertidos em funções psicológicas. Vigotski (2010), sustentando-se nesses pressupostos, considera que a "aprendizagem da criança começa muito antes da aprendizagem escolar. A aprendizagem escolar nunca parte do zero. Toda aprendizagem da criança na escola tem uma pré-história” (VIGOTSKI, 2010, p. 109, grifos do autor).

Ao falarmos de aprendizagem, de acordo com a perspectiva sócio-histórica, consideramos necessário o debate a respeito da formação de conceitos. Para Vigotski (2000), quando tratamos de conceito, estamos falando da ligação do saber verbal com a realidade experimentada e vivida pela criança. Logo, analisar a maneira pelo qual o conceito é utilizado pela criança é confrontar o conteúdo verbal com situações de relação da criança com o mundo. Sobre isso, Friederich (2012) afirma que dois elementos se destacam nos estudos desse autor. O primeiro é sua concepção de linguagem segundo a qual o fenômeno do uso da palavra está na base da formação de conceitos. O segundo elemento é a afirmação de que as formas de conceitualização se modificam ao longo do desenvolvimento, apresentando, na criança em fase escolar, características distintas. A seguir buscaremos, de forma sintética, analisar os estágios de formação conceitual a fim de investigar em que consiste a natureza de um pensamento conceitual segundo a perspectiva sócio-histórica, com base na obra A construção do Pensamento e da Linguagem (VIGOTSKI, 2000). A faixa etária das crianças, em cada estágio apresentado pelo autor para debater a formação conceitual, não é pormenorizada, porém podemos inferir que se trata de etapas da primeira infância até a fase adulta. 
O primeiro estágio é o dos conceitos sincréticos, quando a criança designa diferentes objetos utilizando a mesma palavra, por exemplo, situações espaciais ou temporais, em uma configuração específica, ou mesmo objetos nessa configuração, provocada especialmente pela percepção e pela ação. Apesar de conseguir comunicar ao adulto algumas palavras sobre alguns objetos, internamente o significado ainda é difuso, como expõe Vigotski (2000, p. 175): “o significado da palavra é um encadeamento sincrético não enformado de objetos particulares que, nas representações e na percepção da criança, estão mais ou menos concatenados em uma imagem mista”. Friederich (2012) afirma que já nesse estágio podemos encontrar elementos de generalização, pois tais nexos subjetivos, amparados pela ação, dão às crianças possibilidades de realizar um processo de seleção sobre quais nexos poderão servir à construção do significado da palavra.

O segundo tipo de conceitos analisados são os complexos. A criança torna-se capaz de atribuir elementos a uma palavra, pelo estabelecimento de relações concretas e aparentes. Ela já é capaz de categorizar, isto é, classificar ou reunir objetos em categorias por cores, tamanhos ou por tipos de objeto. Segundo Vigotski (2000), a variedade do pensamento (em termos funcionais), nessa etapa, conduz à formação de vínculos, ao estabelecimento de relações, à unificação e generalização de objetos particulares, ou seja, à sistematização de toda experiência da criança (VIGOTSKI, 2000). As leis que a criança utiliza para categorizar o que vive no mundo concreto são próprias e objetivas, constituindo um modo de generalização de traços de objetos surgidos na experiência prática.

Com base no estabelecimento de categorias do pensamento por complexos, Vigotski (2000) descreve um tipo de formação conceitual, que particularmente nos interessa neste trabalho, que são os pseudoconceitos. A formação do pseudoconceito ocorre pela categorização de conceitos já elaborados pela criança em suas generalizações, associada a situações ou objetos concretos (ações práticas), contudo, comparativamente ao primeiro estágio (pensamento sincrético), é qualitativamente mais elaborada, pois na formação conceitual há uma tentativa de se aproximar da relação de linguagem que a criança vive por meio da experiência com adultos. Por exemplo, a criança só é capaz de afirmar que laranja e banana são frutas, uma vez recebida essa informação de um adulto em experiências sociais nas quais os termos que nomeiam essas frutas foram utilizados quando da alimentação, no cotidiano. O conceito "fruta" não está diretamente relacionado à laranja e à banana - como é o caso de sua cor, forma ou cheiro - é o adulto que faz para a criança essa generalização. A formação conceitual de "fruta" é constituída no mundo das experiências concretas, mediadas pela palavra de um adulto ou criança mais experiente. Cabe salientar que, mesmo utilizando-se do conceito "fruta" no cotidiano, isso não significa que a criança domine toda a complexidade conceitual envolvida no uso social do termo "fruta". Se, por acaso, a criança que ainda não possui o domínio do conceito (em toda sua complexidade) se deparar com uma fruta nunca vista por ela, poderá não ser capaz de sozinha, concluir que se trata de uma fruta. Vigotski (2000) assim se manifesta a respeito do pseudoconceito:

Através da comunicação verbal com a criança, o adulto pode determinar o caminho por onde se desenvolvem as generalizações e o ponto final desse caminho, ou melhor, a generalização daí resultante. Mas os adultos não podem transmitir à criança seu modo de pensar. Destes ela assimila os significados prontos das palavras, não lhe ocorre escolher por conta própria os complexos e os objetos concretos. (VIGOTSKI, 2000, p. 193).

As leis sobre as quais o pseudoconceito se estrutura são diferentes das que dizem respeito à etapa anterior do desenvolvimento da criança, pois a palavra, talvez pela primeira vez, torna-se o centro gravitacional do significado, e não mais o objeto em si. A criança é 
capaz de formular generalizações por categorias sobre níveis de abstração mais elaborados e assim se aproximar da formação conceitual do adulto.

Desse modo, cria-se uma original situação genética que representa antes uma regra geral que uma exceção em todo o desenvolvimento intelectual da criança. Essa situação original consiste em que a criança começa antes a aplicar na prática e a operar com conceitos que a assimilá-los. O conceito "em si" e "para os outros" se desenvolve na criança antes que se desenvolva o conceito "para si". O conceito "em si" e "para os outros", já contido no pseudo-conceito, é a premissa genética básica para o desenvolvimento do conceito no verdadeiro sentido desta palavra. (VIGOTSKI, 2000, p. 198-199).

O papel da generalização na formação conceitual, e consequentemente em todos os processos que envolvem a aprendizagem no ensino formal, é incontestável segundo as premissas apontadas por Vigotski (2000).

Friederich (2012), outra teórica a tratar desse assunto, assevera que a palavra mostra o seu lugar e a sua importância nesse processo, quando se torna não só a expressão da generalização, mas também suporte desta; isso ocorre quando não fecha o processo nela mesma (na palavra), mas contém em si a possibilidade de generalização. A autora segue esclarecendo que as palavras não representam o mundo em si, mas guiam o processo de pensamento, ou como ela mesma conclui:

[U]tilizar um conceito não significa apenas generalizar, colocar junto às coisas no mundo, mas pensar o mundo, o que pode conduzir a ligações entre as coisas no mundo que não são ligações fatuais [...]. Assim, a linguagem torna presente o pensamento realizado pelos sujeitos em forma de conceitos verdadeiros. (FRIEDERICH, 2012, p. 95-96).

Interpretando o pensamento de Friederich (2012), podemos considerar que o estudo dos conceitos científicos feito por Vigotski (2000) poderá oferecer subsídios ao professor na abordagem dos conceitos desenvolvidos na esfera escolar. Pela distinção entre esse tipo de conceitos e os conceitos cotidianos no que se refere a sua gênese, é possível determinar o papel da escola quanto ao desenvolvimento e à aprendizagem. Assim, um conceito cotidiano refere-se às coisas do mundo, do cotidiano e do concreto (vivências no mundo real) reveladas especialmente nos processos de elaboração do pensamento sincrético e por complexos. Já o conceito científico é considerado uma generalização de segunda ordem, que se realiza por intermédio de outro conceito, mesmo tendo relação com os objetos do mundo (VIGOTSKI, 2000). Compreendemos essa característica de transformação das generalizações já existentes em novos modos de generalização como um dos alicerces sobre os quais poderão ser construídos os fundamentos metodológicos do ensino escolar. De acordo com Vigotski,

[...] [s] a criança forma alguma estrutura no processo educacional, assimila alguma operação, nós descobrimos em seu desenvolvimento não só a possibilidade de reproduzir a referida estrutura, como ainda lhe damos possibilidades bem maiores inclusive no campo de outras estruturas. (VIGOTSKI, 2000, p. 303).

O processo de alfabetização para a criança constitui-se em uma atividade social na qual há a possibilidade de desenvolvimento de conceitos espontâneos trazidos das experiências pessoais do mundo. Na escola, a fim de desenvolver conceitos científicos, o grau de abstração deve possibilitar a simultaneidade da generalização (unir) e da diferenciação (separar), desdobramentos conceituais importantes e implicados na compreensão de conceito científico, com determinação para a compreensão de uma formulação científica. Essa fase 
de ensino escolar, que é a da alfabetização, exige, da criança, tomada de consciência da própria atividade mental, porque nessa etapa é desenvolvida uma relação especial com o objeto de conhecimento agora em processo de sistematização, o que conduz à internalização do que é essencial do conceito e à compreensão deste no sistema complexo das relações nas quais está inserido. Para Vigotski (2000), o caráter consciente e o caráter voluntário da apreensão (domínio) das elaborações conceituais na aprendizagem escolar traduzem-se em nova formação psíquica, fundamental para a formação conceitual. Vigotski afirma: "[v]emos que toda aprendizagem escolar, tomada no aspecto psicológico, gira sempre em torno do eixo de novas formações básicas da idade escolar: a tomada de consciência e a apreensão" (VIGOTSKI, 2000, p. 321).

Essas interpretações da perspectiva sócio-histórica nos fornecem pistas para compreender o processo de elaboração conceitual das crianças quando em fase inicial de sua experiência como estudantes do ensino fundamental, envolvidas na dinâmica da atividade escolar exigida pelo discurso científico. Mais especificamente, essas reflexões tornam claro o papel da escola no desenvolvimento e na aprendizagem, bem como alertam para a importância do estabelecimento de relações entre a experiência prática e os conceitos científicos na esfera escolar. Permitem-nos ainda pensar que a categorização dos significados em circunstâncias específicas, pela palavra oralizada e escrita, nos fornece indícios para compreender os sentidos e significados do discurso da ciência para a criança (estudante). Os sistemas de generalização utilizados pelas crianças nos textos que escrevem na escola - mesmo que ainda sem o domínio completo do código escrito - são processos discursivos permeados pela linguagem do outro que lhe permitem dizer sua própria palavra.

A tomada de consciência da criança desses processos, concomitantemente à compreensão de conceitos se dá em uma relação intensa com a palavra (sua X do outro), bem como com o mundo concreto (mundo das atividades humanas - das coisas e das pessoas com as coisas). Todavia, para que possa situar-se como agente e sujeito desse processo, entendemos ser necessário deslocar o enfoque comumente dado à linguagem, (especificamente, no caso aqui em questão à linguagem escrita) na escola. É preciso então entendê-la não apenas como um sistema linguístico de códigos, mas também e sobretudo apreendê-la em sua dimensão dialógica, interlocutiva. Smolka (2012), em sua relevante pesquisa a respeito do processo discursivo na alfabetização, defende essa mudança de enfoque:

Se tomarmos, então, o texto - e suas condições de produção como unidade de análise, isto é, se da análise fonética, ortográfica, lógica ou gramatical, deslocarmos o enfoque para a questão da constituição do sentido e perguntarmos: como a criança se colocou nesse espaço de interlocução? Que posição ela assumiu para escrever o que escreveu? - vamos perceber os indicadores de uma intensa atividade mental, cognitiva, discursiva, que revelam a elaboração da relação pensamento/linguagem no processo de escritura. (SMOLKA, 2012, p. 117, grifo da autora).

Quando o texto, concebido como enunciado (BAKHTIN, 2011), como objeto para conhecer o que a criança pensa sobre ciências, podemos nele encontrar indícios dos domínios conceituais da linguagem em si, como também dos sistemas conceituais do discurso científico formados no decurso da história da humanidade. Além disso, podemos inferir que o processo de elaboração conceitual desenvolvido na esfera escolar pode ser considerado como um modo de a criança se colocar no mundo e escrever sobre isto. 


\section{Caminhos do aprender: sentidos e significados na aquisição de conceitos das Ciências}

No intento de examinarmos como os sentidos são constituídos em uma prática de linguagem selecionamos um evento ocorrido na turma de segundo ano relacionado com o projeto de estudo escolhido pelos alunos e professores ${ }^{2}$, o qual teve como foco o estudo do entorno do Colégio de Aplicação da UFSC, especificamente no que se refere à fauna e à flora. As crianças intitularam esse estudo de O Matagal do Colégio de Aplicação.

A metodologia utilizada para a coleta de dados foi a análise de cunho sócio-histórico, pela qual se busca analisar as relações dialógicas existentes em processos e produtos humanos (BAKHTIN, 2011). Pretendemos dar visibilidade ao processo vivenciado por partícipes desse espaço, professor e alunos, analisando suas inter-relações no processo de alfabetização envolvendo a linguagem científica. A coleta de dados foi realizada em um período de quatro meses e envolveu: 1) registro via filmagem, gravação de áudios e fotografias do campo de coleta (a sala de aula ou outros espaços da escola que fizeram parte do processo pedagógico). Os vídeos geraram 135 horas de gravação, das quais foram retirados excertos para análise; 2) Diário de Campo, em que fazíamos anotações ao final de cada dia de coleta de dados, registrando as impressões sobre o trabalho pedagógico com as crianças, suas relações com as atividades propostas; e 3) produção de textos escritos por alunos e pela turma, realizados no período da coleta de dados, devidamente escaneados para uso como dado de pesquisa.

Realizamos, como professora da turma, em conjunto com os alunos, um levantamento dos assuntos que eles gostariam de abordar durante o estudo, com o objetivo de estabelecer diretrizes ao planejamento da proposta de ensino pela qual se previa o trabalho com diferentes áreas do conhecimento, bem como direcionar o foco a um determinado assunto ou tema. Abaixo, podemos ler um excerto do Diário de Campo da nossa pesquisa em que destaco as perguntas feitas pelas crianças:

\begin{abstract}
Após regressarmos à sala de aula, realizamos no quadro um levantamento coletivo de dúvidas e perguntas dos alunos a respeito do que viram [no matagal]. Na análise das questões, pude resumi-las e organizá-las em torno dos seguintes temas: espaço do matagal (que coisas existem lá, como são os lugares); plantas (tipos de plantas, árvores, tamanhos das plantas); animais (que animais vivem lá; como eles morrem, para onde eles vão depois que morrem). De alguma forma, as conversas dos alunos convergiram para um assunto não esperado que foi a questão da morte dos animais. Especialmente os alunos Eduardo, Tiago, Godofredo, Samy e Flora. As questões deles sobre este último tema vinham misturadas com um grande entusiasmo na fala e com muitas hipóteses. (MARTINEZ, 2015, p. 149).
\end{abstract}

Com base na percepção de um entusiasmo diferenciado dos alunos por tal questão, a realização de um trabalho pedagógico focado na questão da decomposição de seres vivos foi delineando-se. O planejamento organizado previu a leitura e consequente debate de textos de divulgação científica e informativos (folheto), observações do espaço geográfico que é o Matagal, visita de um especialista na área das ciências biológicas que forneceu informações sobre o tema, experiências sobre decomposição da matéria orgânica e produção de registros sobre as observações realizadas.

Para nossa análise selecionamos, do conjunto dessas propostas de atividade o registro de uma experiência sobre seres decompositores. A experiência consistia na observação do processo de decomposição de alguns alimentos (laranja, pão de forma e maracujá) trazidos pelos alunos e que foram acondicionados em potes de vidro e sacos plásticos totalmente fechados para observação do processo de decomposição. Ao longo
$2>$ Os dados aqui apresentados foram coletados dentro do contexto da pesquisa de mestrado de Martinez (2015). 
das semanas, realizávamos rodas de conversa para avaliarmos os resultados da experiência e posteriormente realizarmos o registro escrito.

Nas anotações, os alunos foram estimulados a usar a escrita espontânea de pequenas frases com as informações principais sobre a experiência naquele dia. Após a escrita espontânea, a professora realizava intervenções em aula com o intuito de auxiliar na elaboração das frases, dúvidas gramaticais ou mesmo na escrita de palavras, para aqueles que ainda não dominavam a escrita alfabética.

O trecho transcrito abaixo é demonstração de um evento de "roda de conversa" sobre a experiência em questão, gravado em vídeo e onde a letra P representa a fala da professora e a letra $\mathrm{C}$ a fala da criança seguida de seu codinome ${ }^{3}$ :

[Vídeo 1 - Episódio 1]

1. P Débora: A gente vai conversar um pouquinho antes do registro. Quem é que lembra qual era o objetivo dessa experiência?

2. C Sófi: As coisas apodrecerem.

3. P Débora: As coisas apodrecerem. Quem mais quer falar?

4. C Samanta: E também os fungos e as bactérias aparecerem.

5. P Débora: Muito bem. Alguém mais?

6. C Sófi: Eu tava lá na minha casa, tinha uma laranja na fruteira podre. Ela ficou mole e ficou mofada igual o pão.

7. P Débora: A Sófi está dando um exemplo de algo que ela já observou.

8. C Paulo: Eu também.

9. P Débora: Então, você quer falar?

10. C Paulo: Eu também já vi uma laranja... [interrupção da fala]

11. P Débora: Conta como é que você viu a laranja.

12. C Paulo: Eu fui pegar assim e qualquer coisa [fica em silêncio por alguns segundos] eu toquei lá naquilo...

13. P Débora: E como era o aspecto dela? O que você via para saber se ela estava podre?

14. C Paulo: Era verde.

15. C Sófi: Era da cor desta casquinha? [aponta para a casca do pão que está apodrecido no pote]

16. C Paulo: É. E era bem mole assim... [fazendo uma careta e gestos com as mãos]

17. C Samanta: Profe, olha o que que tem aqui no pão olha...Essa coisa aqui...

18. C Sófi: É branco.

19. C Edson: Espuma branca!

20. P Débora : Então quem sabe começamos a passar os potes para cada um pegar... [Barulho, falas conjuntas]

21. P Débora: Calma, eu vou explicar, vamos fazer assim... A gente vai passar de mão em mão, pode olhar de perto, cuidado para não cair e aí cada um vai olhar e explicar o que acha que aconteceu e se repetir não tem problema, tá bom? [...]

22. C Mati [com o pote na mão]: É algodão.

23. C Fernando: Que algodão?

24. P Débora: É, tem uma parte do pão com aspecto de algodão, né?

25. C Edson: Mas não é o pss, pss, pss [barulho com a boca e gesto com a mão]?

26. P Débora: O que você quer dizer com pss pss pss?

27. C Edson: É porque parece a coisa da aranha.

28. C Fernando: A teia da aranha. (MARTINEZ, 2015, p. 150-152).

3 > Os nomes e identidades das crianças foram protegidos por codinomes escolhidos pelas mesmas.

Pela perspectiva sócio-histórica, as variáveis de linguagem que possibilitaram a existência desse diálogo em particular, e de seus temas (sentidos), são apenas uma das possibilidades entre todos os enunciados que poderiam, sob condições diferentes, preencher uma posição de existência na relação dialógica. Foram os sujeitos protagonistas desse evento que possibilitaram, por sua posição histórica no mundo, criar estes enunciados específicos: 
[Vídeo 1 - Episódio 1]:

1. C Edson: Espuma branca!

2. C Mati [com o pote na mão]: É algodão.

3. C Edson: É porque parece a coisa da aranha.

4. C Fernando: A teia da aranha. (MARTINEZ, 2015, p. 152).

Os alunos Sófi e Paulo, em especial, trouxeram para esse diálogo suas vivências pessoais, relacionando uma atividade escolar com um evento cotidiano em suas casas. Assim que a professora possibilitou à turma fazer comentários sem uma pergunta que direcionasse a resposta, os dois alunos posicionaram-se por meio do relato de suas vivências. Tomando como base o episódio, podemos inferir que os sujeitos buscaram na vivência cotidiana, em suas histórias pessoais de outros ambientes sociais, a base conceitual (pensamento) para compreender o processo de apodrecimento dos alimentos. Conforme afirma Bakhtin, toda enunciação é marcada por um tom, separado dos elementos fônicos e semânticos da palavra, que serve "de contexto axiológico-emocional na nossa interpretação (plena e centrada nos sentidos) do texto que lemos (ou ouvimos), bem como em uma forma mais complexa e no processo de criação (de geração) do texto" (BAKHTIN, 2011, p. 403).

Ao observarmos um pouco mais a fala de Paulo, podemos refletir sobre como o contexto emocional, histórico e social no qual a criança produz linguagem conduz esse momento de atividade escolar. O aluno contribui com o grupo falando de sua experiência cotidiana, mas está visivelmente incomodado com o fato de lidar com os elementos presentes na experiência concreta que partilhou na escola (o pão mofado, a laranja decompondo-se). Paulo tenta participar da discussão do grupo, mas ao fazê-lo dá indícios de seu incômodo: utiliza as palavras "coisa" e "naquilo" para referir-se ao alimento decomposto; fica em silêncio no meio de sua sentença e utiliza o próprio corpo para expressar gestos de desconforto, indicativos de nojo, repugnância ao estado de decomposição do pão. Talvez este seja um dos componentes que levaram Paulo a não participar novamente da conversa e permanecer em silêncio, limitando-se a observar o que diziam os colegas. De acordo com Bakhtin (2011), a produção de sentidos é perpassada por condições emocionais como a que estamos relatando, e ao encontrar um ambiente social (a escola) em que foi desafiado a pensar sobre esta questão, Paulo encontrou alguns entraves para refletir sobre o tema proposto. Poderíamos pensar, portanto, que o aluno criou um texto no contexto escolar e deu a ele as possibilidades linguísticas de que dispunha no momento, ou seja, o silêncio, por não se sentir confortável com o tema. Talvez a mesma estratégia didático-científica com outro tema poderia provocar tom diverso à fala de Paulo e, consequentemente, à produção de novos sentidos. Assim como, a exploração deste tema por intermédio de outras propostas de atividades poderia conduzir a outras formas de reação-resposta a esse objeto do conhecimento.

Sobre a produção de sentidos, podemos nos deter no texto produzido por Edson ao longo do tempo em que a rodinha de conversa esteve formada. Suas falas são específicas ao fenômeno do mofo branco que surgiu sobre o pão. Quando o grupo tratou de discutir esse tema, Edson mostrou-se interessado em falar e participar do debate, pontuando que se tratava de uma espuma branca. Em seguida, Mati elabora a hipótese sobre o que seria a camada branca presente no pão dizendo que era algodão. Em seguida, Edson retoma a fala, ao utilizar uma onomatopeia - "pss, pss, pss" - para expressar sua hipótese. É o colega Fernando que auxilia na interpretação e na formulação da ideia de Edson de que ele estaria se referindo a uma teia de aranha. Ao analisar os recursos linguísticos de Edson para imitar o som produzido por aranhas, naquele momento em especial, notamos que houve vinculação com um desenho animado comum entre as crianças da turma, O homem aranha, no qual o personagem principal lança teias pelos pulsos e realiza o barulho semelhante ao que o aluno proferiu. Edson concordou com o colega que se tratava 
da teia de aranha e, partilhando da produção oral alheia, pôde sustentar a sua própria hipótese diante dos colegas.

As relações dialógicas que os enunciados estabelecem nos eventos de oralidade partilhada podem ser mola propulsora para o desenvolvimento da linguagem tanto oral como a escrita (nosso objeto investigado) das crianças. A compreensão dos enunciados, seu tema, estilo e composição podem ser apreendidos como forma de assegurar, mas acima de tudo, aprofundar a materialização do projeto de dizer do autor.

No caso em análise, Edson descobriu na expressão "pss, pss, pss" o potencial para transformá-la em explicação para o questionamento do professor. Bakhtin (2011) esclarece que a "coisa" por si só não é capaz de produzir sentidos. Segundo ele, "[a] coisa, ao permanecer coisa, pode influenciar apenas as próprias coisas; para influir sobre os indivíduos ela deve revelar seu potencial de sentidos, isto é, deve incorporar-se ao eventual contexto das palavras e sentidos" (BAKHTIN, 2011, p. 404, grifos do autor). Podemos pensar que a experiência em si da observação de eventos da natureza partilhada com a experiência da palavra na relação eu/outro constitui um evento propulsor de sentidos que poderá contribuir nos processos de aprendizagem dos alunos; é a palavra incorporada ao mundo e as coisas.

Smolka (2012) compreende o processo da alfabetização como processo discursivo, fato que potencializa, no espaço escolar, diferentes modos de ver e dizer o mundo; qualifica o ensino e a aprendizagem na atividade pedagógica do ensinar a ler e a escrever, neste que é compromisso da educação básica. Ainda, amparada na perspectiva sócio-histórica, a autora esclarece que "por trás das palavras existe uma gramática própria do pensamento, existe uma sintaxe dos sentidos das palavras. Essa gramática, essa sintaxe, tem origem nas formas sociais de interação verbal, mas é permeada por uma realidade psicológica, individual" (SMOLKA, 2012, p. 84).

Voltando ao evento em discussão, após o término da roda de conversas desse dia, as crianças foram convidadas a retornar às suas mesas e realizar o registro na folha estruturada já apresentada. Cada aluno, conforme já apontamos, poderia escrever aquilo que mais lhe chamou a atenção nos três alimentos em decomposição (laranja, pão ou maracujá). Além disso, a escrita não tinha que, necessariamente, relacionar-se com aquilo que foi debatido na roda de conversas. Vejamos agora como alguns alunos partícipes do evento realizaram o registro escrito. Selecionamos os textos de Mati, relativos ao dia do evento em questão, bem como os anteriores e o posterior à mesma atividade, que foi sendo construído ao longo de algumas semanas:

Figura 1 - Mati, texto 1

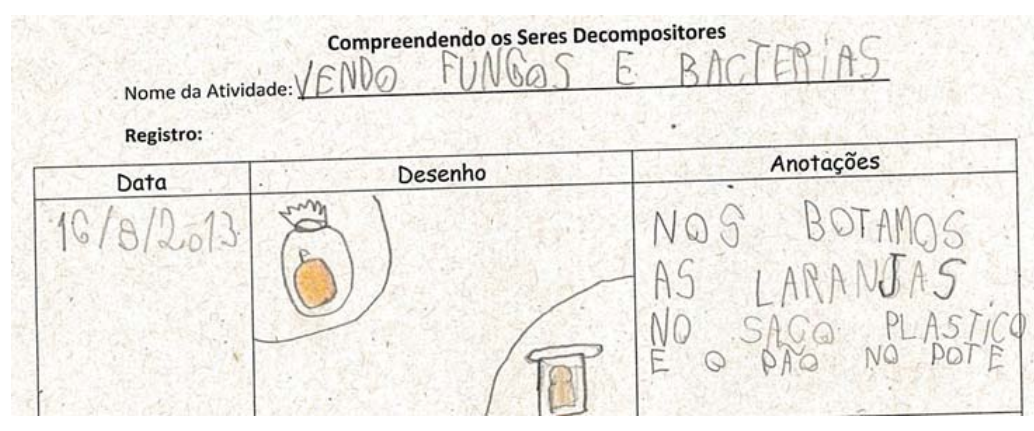

Fonte: Martinez (2015, p. 155).

"NÓS BOTAMOS AS LARANJAS NO SACO PLÁSTICO E O PÃO NO POTE" 
Figura 2 - Mati, texto 2

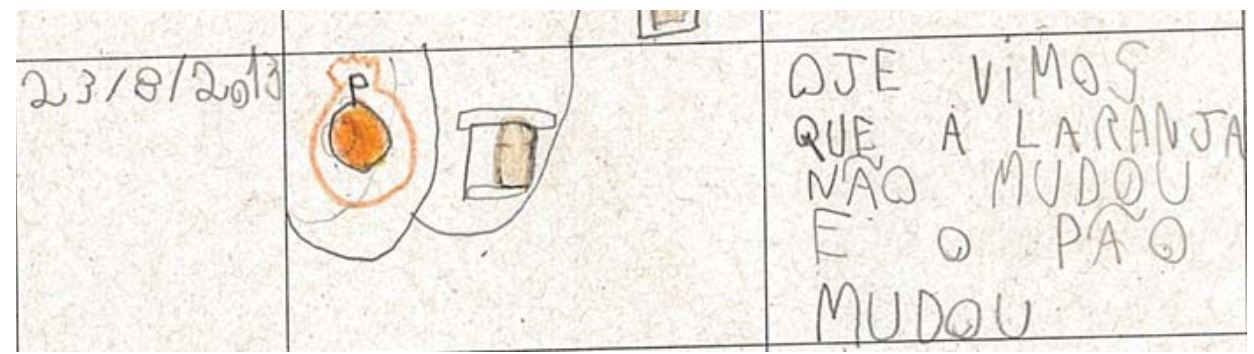

Fonte: Martinez (2015, p. 156).

“HOJE VIMOS QUE A LARANJA NÃO MUDOU E O PÃO MUDOU”

Figura 3 - Mati, texto 3

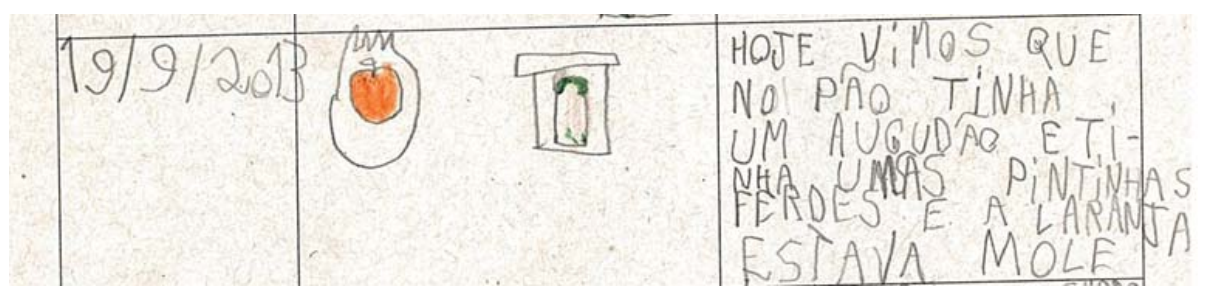

Fonte: Martinez (2015, p. 156).

“HOJE VIMOS QUE NO PÃO TINHA UM ALGODÃO E TINHA UMAS PINTINHAS VERDES E A LARANJA ESTAVA MOLE"

Figura 4 - Mati, texto 4

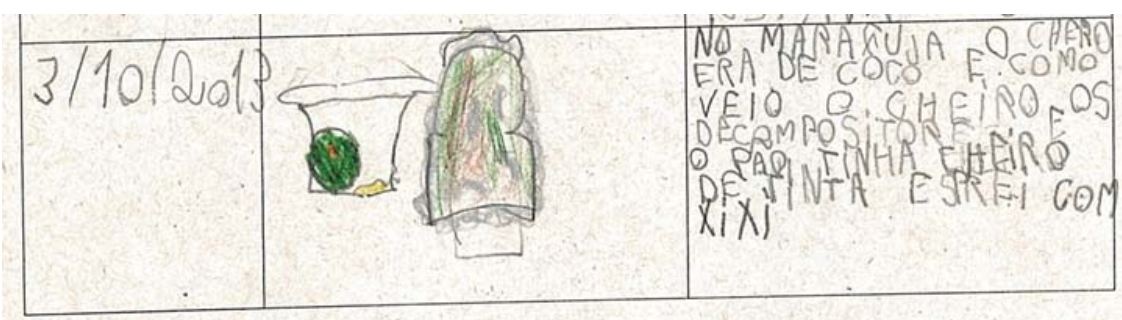

Fonte: Martinez (2015, p. 157)

“NO MARACUJÁ O CHEIRO ERA DE COCÔ E COMO VEIO O CHEIRO E OS DECOMPOSITORES O PÃO TINHA CHEIRO DE TINTA SPRAY COM XIXI"

No registro do texto 3, em que Mati diz "hoje vimos que no pão tinha um algodão", o aluno busca comparar o que foi possível observar pela experiência vivida, com elementos que conhece, no caso o algodão, e, nessa possibilidade da resolução ao questionamento da professora, consegue produzir sentidos naquela situação de conversa pedagógica, conseguindo, possivelmente, avançar em seu processo de aprendizagem. Advoga Vigotski: “[o] sentido real de cada palavra é determinado, no fim das contas, por toda a riqueza dos momentos existentes na consciência e relacionados àquilo que está expresso por determinada palavra" (VIGOTSKI, 2000, p. 466). A palavra, portanto, tem um papel fundamental na elaboração de Mati pois é ela que condensa uma série de experiências e de significados já partilhados socialmente por essa criança.

Os sentidos elaborados são oriundos de um processo de experiência e convívio social, bem como dos processos singulares do sujeito que está em constante movimento de internalização da linguagem. Na utilização da palavra escrita, Mati avança na produção de sentidos a respeito do seu meio social, ampliando o conceito da palavra algodão. Seguindo 
a perspectiva teórica de Vigotski (2000), as práticas com a linguagem — seu uso e reflexão sobre elas - permitirão ao sujeito alcançar a complexidade dos conceitos científicos em relação aos conceitos cotidianos (VIGOTSKI, 2000). O autor expõe que um dos papéis da linguagem é organizar o pensamento, permitir a generalização e a categorização na mediação dos sujeitos com o mundo. Os conceitos científicos são uma visão de mundo, uma generalização, por isso o trabalho com a linguagem não deve partir dos conceitos sobre a linguagem, mas por meio dela, do seu uso, chegar a eles, os conceitos científicos inerentes à linguagem, aos conhecimentos tratados no curso escolar.

Do conjunto das falas acima, retomemos o enunciado oral de Mati no texto 3, em que, ao pegar o pote da experiência, afirma: “é algodão". Após a sua fala, a professora intervém, dizendo que se trata do aspecto do pão. Logo em seguida, o colega Edson traz para a roda de conversa outra hipótese para a mesma questão, a de que o aspecto branco seria uma teia de aranha. Mesmo com essas possibilidades de construção de novos sentidos para a experiência, parece que Mati encontra no conceito algodão a explicação de que necessita para aquele processo de decomposição do pão. O aluno reafirma sua hipótese e a defende como tese em seu registro escrito, sustentando o argumento: "tinha um algodão" (manutenção da posição discursiva, individual). Podemos considerar que Mati utilizou a fala para organizar seu pensamento, assim como defende Vigotski (2000), constituindose um sujeito interativo no processo de elaboração conceitual ao fazer a defesa do que diz ter visto. Foi no grande grupo que disputou sentidos, confrontou-se com as palavras dos outros, a dos colegas, da professora (voz de autoridade) como contrapalavra, uma experiência que se aproximaria do que Bakhtin chama de uma atitude "responsiva ativa" diante da palavra proferida pelo outro, o locutor (BAKHTIN, 2010).

A contribuição de Mati à roda de conversas evoca a ideia de Bakhtin (2010) segundo a qual para o locutor não importa o sistema linguístico em si — significado —, mas aquilo que torna a palavra signo em uma determinada situação concreta de produção de linguagem. Quando esse aluno assume a palavra algodão para explicar um processo natural que é o mofo do pão, traz para o grupo uma possibilidade de sentido outro. O meio social escolar possibilitou a Mati e a seus colegas realizarem a reflexão sobre um fenômeno de natureza biológica e buscarem em seus repertórios de linguagem palavras que pudessem explicar a experiência, com foi o caso de Mati, Édson e Fernando.

A sistematização por escrito que Mati fez do conjunto das observações da experiência sobre decomposição é traço claro de sua experiência na prática a qual descreveu com objetividade e idiossincrasia. Mesmo tendo contato com as aulas sobre decomposição (leitura de textos específicos sobre o assunto) ainda elabora sentidos a partir de conceitos cotidianos selecionando palavras que julga adequadas (VIGOTSKI, 2000), como tentativa válida de produzir significados e sentidos sobre o discurso científico. Além disso, as hipóteses do aluno são fundadas nas próprias possibilidades de cada etapa do desenvolvimento infantil pois, segundo Vigotski (2000),

[...] o processo de desenvolvimento dos conceitos ou significados das palavras requer o desenvolvimento de toda uma série de funções como atenção, arbitrária, a memória lógica, a abstração, a comparação e a discriminação, e todos esses processos psicológicos não podem ser simplesmente memorizados, simplesmente assimilados. (VIGOTSKI, 2000, p. 246).

A produção de Mati nos lembra que o conceito ou significado da palavra é histórico e que sua apreensão é processual. Apesar de naquele momento o aluno ter considerado que o processo biológico poderia ser explicado pela ideia de que era algodão, ele teve a possibilidade de, pela escuta do outro, ter acesso às outras hipóteses que poderão enriquecer as possibilidades de generalização e elaboração desse conceito em outra atividade escolar. 
O mesmo ocorre quando o aluno compara no registro do texto 4 o cheiro desagradável do pão com "tinta e spray com xixi”. Mati se vale de enunciados que lhes são familiares para a produção de seu enunciado próprio-alheio, para fazer-se entender diante do(s) outro(s) mas especialmente para si mesmo. A escrita aqui toma um papel de reguladora do conhecimento e das vivências da criança. Mati usa aquilo que responde às suas inquietações, vivências, emoções no processo de produção da linguagem e a escrita, como palavra-própria e palavra do outro, sintetiza esse momento de sua rota em direção à sistematização de conceitos na escola. Como nos disse Bakhtin, não há sentido em si, somente em contato com o sentido do outro (BAKHTIN, 2011).

\section{Considerações finais}

As atividades discursivas no contexto de sala de aula são construções coletivas, nas quais os significados vão sendo produzidos e apropriados pelos que delas participam. Muitas vozes se entrecruzam em sua produção, vozes presentes no campo da enunciação (falante-ouvinte) e também aquelas de vozes ausentes, próximas ou distantes, advindas de outros contextos influentes nessa produção: familiar, institucional, cultural e social. Também elas (as atividades discursivas) são condicionadas pelas circunstâncias do momento concreto de sua ocorrência, dependente ainda do que se fala ou fez antes, bem como das expectativas do que pode ser dito ou feito posteriormente. Assim, uma atividade com uma intencionalidade pedagógica definida desencadeia modos de realização diferentes e promove construções e aprendizagens distintas, posto que estas estão submetidas a uma multiplicidade de circunstâncias influentes. As relações sociais que estão na base da construção do conhecimento e do desenvolvimento da humanidade materializam-se nas redes de interações que se entrecruzam nos cenários culturais particulares.

Os movimentos de constituição de sentidos e elaboração de conceitos partem da experiência prática, sustentados por certa estabilidade de significados que a criança já domina. A emergência de novas elaborações conceituais é evidenciada por meio dos processos de interlocução, observados em nossa análise na relação entre enunciados orais e escritos. Ao colocar-se em diálogo com o outro (professora e seus pares) a criança coloca sua palavra à avaliação viva pela reação alheia. Assim, a palavra passa a ampliar-se para além do sistema linguístico em si e recebe lugar nas tantas possibilidades enunciativas que lhe podem ser dadas. De acordo com o que nos diz Bakhtin, ao longo de suas obras, é oferecer à palavra a possibilidade da contrapalavra, na ordem dialógica das relações de sentido.

Tanto a roda de conversas quanto os textos apresentados trouxeram elementos que nos permitem afirmar que a oralidade ainda sustenta boa parte do fluxo de suas escritas. Contudo, percebemos que muitos deles já traçam estratégias específicas para o discurso escrito, as quais, diferenciando-se do enunciado oral, demonstram a preocupação do sujeito-escritor com seu interlocutor, com seu projeto de dizer, com o fazer-se compreender pelo outro. Nesse processo, a mediação da professora nas diversas atividades propostas evidenciou-se nos textos, sustentando a ideia de que na etapa de alfabetização os alunos necessitam ter acesso à palavra do outro no desenvolvimento de suas capacidades de uso da língua. E essa palavra está nos dizeres da professora e dos colegas, nos textos lidos, nas histórias contadas, nos livros da biblioteca aos quais as crianças tiveram acesso, em uma relação intensa com processos de letramento.

A linguagem (palavra), como produto do meio social foi o que possibilitou a inserção das crianças no universo dos conceitos do discurso das ciências, desenvolvendo o processo 
de tomada de consciência de um conceito científico. Contudo, percebemos que foram os conceitos espontâneos, os significados que as crianças já dominavam que permitiram a emergência da elaboração dos conceitos específicos do conhecimento científico. Daí a importância de acolhermos a linguagem que a criança traz para a escola, pois ela representa o primeiro degrau pelo qual a criança chega ao conhecimento científico. Além disso, como pesquisadores de um projeto de iniciação científica na escola, as crianças tiveram espaços e tempos para que a palavra pudesse ir se ressignificando, estabelecendo novos elos de sentido. Um projeto de ensino na etapa de alfabetização, ao prever a recepção e circulação dos discursos por uma gama diversa de atividades direcionadas à área das ciências, promove reflexões sobre os conceitos científicos, num processo de idas e vindas, dado que os sentidos são sempre inacabados. A exploração da palavra em suas inúmeras possibilidades enriquece e amplia as condições concretas dos estudantes de lidar com conceitos científicos.

Ao longo do projeto de ensino "Matagal do CA" e da apropriação de conceitos próprios do discurso das ciências, os alunos começaram a utilizar termos específicos da área em suas escritas, alguns com mais propriedade e outros, mesmo com pouco domínio de uso desses termos, como forma de legitimar um texto do gênero discursivo do campo científico. Tais movimentos do uso da palavra são, como advoga Vigotski (2000), novas estruturas de generalização e abstração que não anulam as anteriores, mas as transformam em estruturas de significação mais complexas. Dessa maneira, na fase escolar, não são criados conceitos para cada novo estágio, mas recriados pela criança, por intermédio da palavra como condutora desse novo plano do desenvolvimento.

\section{Referências}

BAKHTIN, Mikhail. Estética da criação verbal. Tradução de Paulo Bezerra. 6. ed. São Paulo: Martins Fontes, 2011.

BAKHTIN, Mikhail. Marxismo e filosofia da linguagem. Tradução de Michel Lahud e Yara Frateschi. 14. ed. São Paulo: Hucitec, 2010. Originalmente publicado sob o nome Valentín Volochínov.

FRIEDERICH, Janette. Lev Vigotski: mediação, aprendizagem e desenvolvimento: uma leitura filosófica e epistemológica. Tradução de Anna Rachel Machado e Eliane Gouvêa Lousada. São Paulo: Mercado das Letras, 2012.

MARTINEZ, Débora Ferrari Martinez. A Escrita nos Anos Iniciais do Ensino Fundamental: domínios de sentido na linguagem científica. 2015. Dissertação (Mestrado em Educação) - Centro de Ciências da Educação, Universidade Federal de Santa Catarina, Florianópolis, 2015.

SMOLKA, Ana Luiza. A criança na fase inicial da escrita: alfabetização como processo discursivo. 13. ed. São Paulo: Cortez, 2012.

VIGOTSKI, Lev. Aprendizagem e desenvolvimento intelectual na idade escolar. In: VIGOTSKI, Lev; LURIA, Alexander; LEONTIEV, Alex. Linguagem, desenvolvimento e aprendizagem. São Paulo: Ícone, 2010. p. 103-118.

VIGOTSKI, Lev. A construção do pensamento e linguagem. Tradução de Paulo Bezerra. São Paulo: Martins Fontes, 2000.

VIGOTSKI, Lev. Obras escogidas IV. Madri: Visor, 1997. 